\title{
Dietary intake of advanced glycation endproducts is associated with higher levels of advanced glycation endproducts in plasma and urine: The CODAM study
}

Citation for published version (APA):

Scheijen, J. L. J. M., Hanssen, N. M. J., van Greevenbroek, M. M., van der Kallen, C. J., Feskens, E. J. M., Stehouwer, C. D. A., \& Schalkwijk, C. G. (2018). Dietary intake of advanced glycation endproducts is associated with higher levels of advanced glycation endproducts in plasma and urine: The CODAM study. Clinical Nutrition, 37(3), 919-925. https://doi.org/10.1016/j.clnu.2017.03.019

Document status and date:

Published: 01/06/2018

DOI:

10.1016/j.clnu.2017.03.019

Document Version:

Publisher's PDF, also known as Version of record

\section{Document license:}

Taverne

Please check the document version of this publication:

- A submitted manuscript is the version of the article upon submission and before peer-review. There can be important differences between the submitted version and the official published version of record.

People interested in the research are advised to contact the author for the final version of the publication, or visit the DOI to the publisher's website.

- The final author version and the galley proof are versions of the publication after peer review.

- The final published version features the final layout of the paper including the volume, issue and page numbers.

Link to publication

\footnotetext{
General rights rights.

- You may freely distribute the URL identifying the publication in the public portal. please follow below link for the End User Agreement:

www.umlib.nl/taverne-license

Take down policy

If you believe that this document breaches copyright please contact us at:

repository@maastrichtuniversity.nl

providing details and we will investigate your claim.
}

Copyright and moral rights for the publications made accessible in the public portal are retained by the authors and/or other copyright owners and it is a condition of accessing publications that users recognise and abide by the legal requirements associated with these

- Users may download and print one copy of any publication from the public portal for the purpose of private study or research.

- You may not further distribute the material or use it for any profit-making activity or commercial gain

If the publication is distributed under the terms of Article $25 \mathrm{fa}$ of the Dutch Copyright Act, indicated by the "Taverne" license above, 
Original article

\title{
Dietary intake of advanced glycation endproducts is associated with higher levels of advanced glycation endproducts in plasma and urine: The CODAM study
}

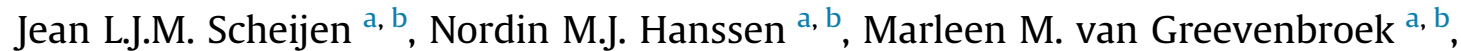 \\ Carla J. Van der Kallen ${ }^{\text {a, b }}$, Edith J.M. Feskens ${ }^{\text {c }}$, Coen D.A. Stehouwer ${ }^{\text {a, b}}$, \\ Casper G. Schalkwijk ${ }^{\text {a, b, * }}$ \\ a Department of Internal Medicine, Laboratory for Metabolism and Vascular Medicine, Maastricht University, Maastricht, The Netherlands \\ b Cardiovascular Research Institute Maastricht, Maastricht, The Netherlands \\ ${ }^{\mathrm{c}}$ Division of Human Nutrition, Section Nutrition and Epidemiology, Wageningen University, Wageningen, The Netherlands
}

\section{A R T I C L E I N F O}

\section{Article history:}

Received 12 September 2016

Accepted 20 March 2017

\section{Keywords:}

Advanced glycation endproducts

Ultra-performance liquid chromatography

tandem mass spectrometry

Food frequency questionnaire

Diet

Maillard reaction

\begin{abstract}
S U M M A R Y
Background \& aims: Advanced glycation endproducts (AGEs) are formed by the reaction between reducing sugars and proteins. AGEs in the body have been associated with several age-related diseases. High-heat treated and most processed foods are rich in AGEs. The aim of our study was to investigate whether dietary AGEs, are associated with plasma and urinary AGE levels.

Methods: In 450 participants of the Cohort on Diabetes and Atherosclerosis Maastricht study (CODAM study) we measured plasma and urine concentrations of the AGEs $\mathrm{N} \varepsilon$-(carboxymethyl)lysine (CML), $\mathrm{N} \varepsilon-$ (1-carboxyethyl)lysine (CEL) and $\mathrm{N} \delta$-(5-hydro-5-methyl-4-imidazolon-2-yl)-ornithine (MG-H1) using UPLC-MS/MS. We also estimated dietary intake of CML, CEL and MG-H1 with the use of a dietary AGE database and a food frequency questionnaire (FFQ). We used linear regression to investigate the association between standardized dietary AGE intake and standardized plasma or urinary AGE levels, after adjustment for age, sex, glucose metabolism status, waist circumference, kidney function, energy- and macro-nutrient intake, smoking status, physical activity, alcohol intake, LDL-cholesterol and markers of oxidative stress.

Results: We found that higher intake of dietary CML, CEL and MG-H1 was associated with significantly higher levels of free plasma and urinary CML, CEL and MG-H1 ( $\beta C M L=0.253$ (95\% CI 0.086; 0.415), $\beta C E L=0.194$ (95\% CI 0.040; 0.339), $\beta \mathrm{MG}-\mathrm{H} 1=0.223(95 \% \mathrm{CI} 0.069 ; 0.373)$ for plasma and $\beta C M L=0.223$ (95\% CI 0.049; 0.393), $\beta \mathrm{CEL}=0.180$ (95\% CI 0.019; 0.332), $\beta \mathrm{MG}-\mathrm{H} 1=0.196$ (95\% CI 0.037; 0.349) for urine, respectively). In addition, we observed non-significant associations of dietary AGEs with their corresponding protein bound plasma AGEs.

Conclusion: We demonstrate that higher intake of dietary AGEs is associated with higher levels of AGEs in plasma and urine. Our findings may have important implications for those who ingest a diet rich in AGEs.
\end{abstract}

๑ 2017 Elsevier Ltd and European Society for Clinical Nutrition and Metabolism. All rights reserved.
*Corresponding author. Department of Internal Medicine, Laboratory for Metabolism and Vascular Medicine, University Hospital Maastricht, P Debeyelaan 25, P.O. Box 5800, 6202 AZ Maastricht, The Netherlands. Tel.: +31 43 3882186; fax: +31433875006 .

E-mail addresses: j.scheijen@maastrichtuniversity.nl (J.L.J.M. Scheijen),nmj.hanssen@ maastrichtuniversity.nl (N.M.J. Hanssen), m.vangreevenbroek@maastrichtuniversity.nl (M.M. van Greevenbroek), c.vanderkallen@maastrichtuniversity.nl (C.J. Van der Kallen), edith.feskens@wur.nl (E.J.M. Feskens), cda.stehouwer@mumc.nl (C.D.A. Stehouwer), c.schalkwijk@maastrichtuniversity.nl (C.G. Schalkwijk).

\section{Introduction}

Advanced glycation endproducts (AGEs) are a large and heterogeneous family of sugar-modified proteins, which have been linked to a plethora of age-related diseases including diabetes, atherosclerosis, chronic obstructive pulmonary disease and Alzheimer's disease [1-3].

In 1912, the French chemist Louis Camille Maillard discovered the reaction between reducing sugars and free amino acids on proteins [4], leading to the formation of AGEs. At body temperature, 
the Maillard reaction takes place at a very slow pace. In contrast, in foods which had a prolonged exposure to high heat AGEs were formed rapidly [5]. The consumption of processed foods that were cooked at high temperatures has increased over the past decades [6]. As a consequence, the exposure to dietary AGEs have also increased and may be a risk factor for chronic diseases [7]. Indeed, recent studies have shown associations of dietary AGEs with insulin sensitivity [8], abdominal obesity and hypertriglyceridemia [9] and with poorer memory in Alzheimer's disease [10]. AGEs in the body may contribute to development of age-related diseases through several mechanisms, such as interaction with the receptor for AGEs (RAGE) [11] and crosslinking on long-lived proteins [12]. However, whether dietary AGEs are substantially absorbed in the digestive tract and released into the circulation to contribute to any of these effects remains unclear.

The studies so far addressing whether high intake of dietary AGEs lead to increased plasma and urinary AGEs have not been conclusive [13-22], because most of these studies have been small and have not taken into account confounding factors such as kidney function or dietary energy intake, which may explain the associations $[19,20]$. Moreover, different analytical techniques to analyze AGE content in food and plasma samples were used in these studies, which may have led to differences in AGE concentrations [21,22].

Taken these considerations into account, the aim of the current study was to establish whether higher intake of dietary AGEs are associated with higher levels of plasma and urinary AGEs. In a previous study, we developed a new dietary AGE database of three major AGEs $\mathrm{N} \varepsilon$-(carboxymethyl)lysine (CML), Ne-(1-carboxyethyl) lysine (CEL) and $\mathrm{N} \delta$-(5-hydro-5-methyl-4-imidazolon-2-yl)-ornithine (MG-H1), as analyzed in 190 specific food items, based on a state-of-the art ultra-performance liquid chromatography tandem mass spectrometry (UPLC-MS/MS) technique [23]. In the present study, we linked information on AGE-content of these food items to a food frequency questionnaire (FFQ) and calculated the consumption of AGEs in a cohort of 465 participants. We subsequently examined the association of dietary AGE intake with three major plasma and urinary AGEs (CML CEL and MG-H1), adjusting for major potential confounders.

\section{Materials and methods}

\subsection{Study population}

Cross-sectional analyses were performed on data from the Cohort on Diabetes and Atherosclerosis Maastricht study (CODAM), which includes 574 individuals with an elevated risk for T2DM and cardiovascular disease and described in detail elsewhere [24]. Participants were instructed to withhold their lipid-lowering medication for a fortnight prior the first visit, and not to consume any alcoholic drinks, coffee and/or tea, not to smoke, and withhold all other medication the day before. The habitual dietary intake over the last twelve months of all participants was established by a selfadministered food frequency questionnaire (FFQ) which queried 194 foods [25].

Individuals were excluded if they did not qualify to report the FFQ successfully ( $n=56$, i.e. more than $10 \%$ items missing on the FFQ). Participants who reported an energy intake outside the range of 800-4200 kcal/day for men and 600-3500 kcal/day for women were also excluded $(n=6)$. Due to sample availability, 450 participants were used for statistical analysis (Fig. 1).

Fasting and 2-h postload glucose concentrations were used to classify the study participants' glucose metabolism status (GMS), described in details elsewhere [26]. Questionnaires were used to assess smoking behavior (never, ever, or current smoker) and use of medication (lipid-, glucose-, and blood pressure-lowering

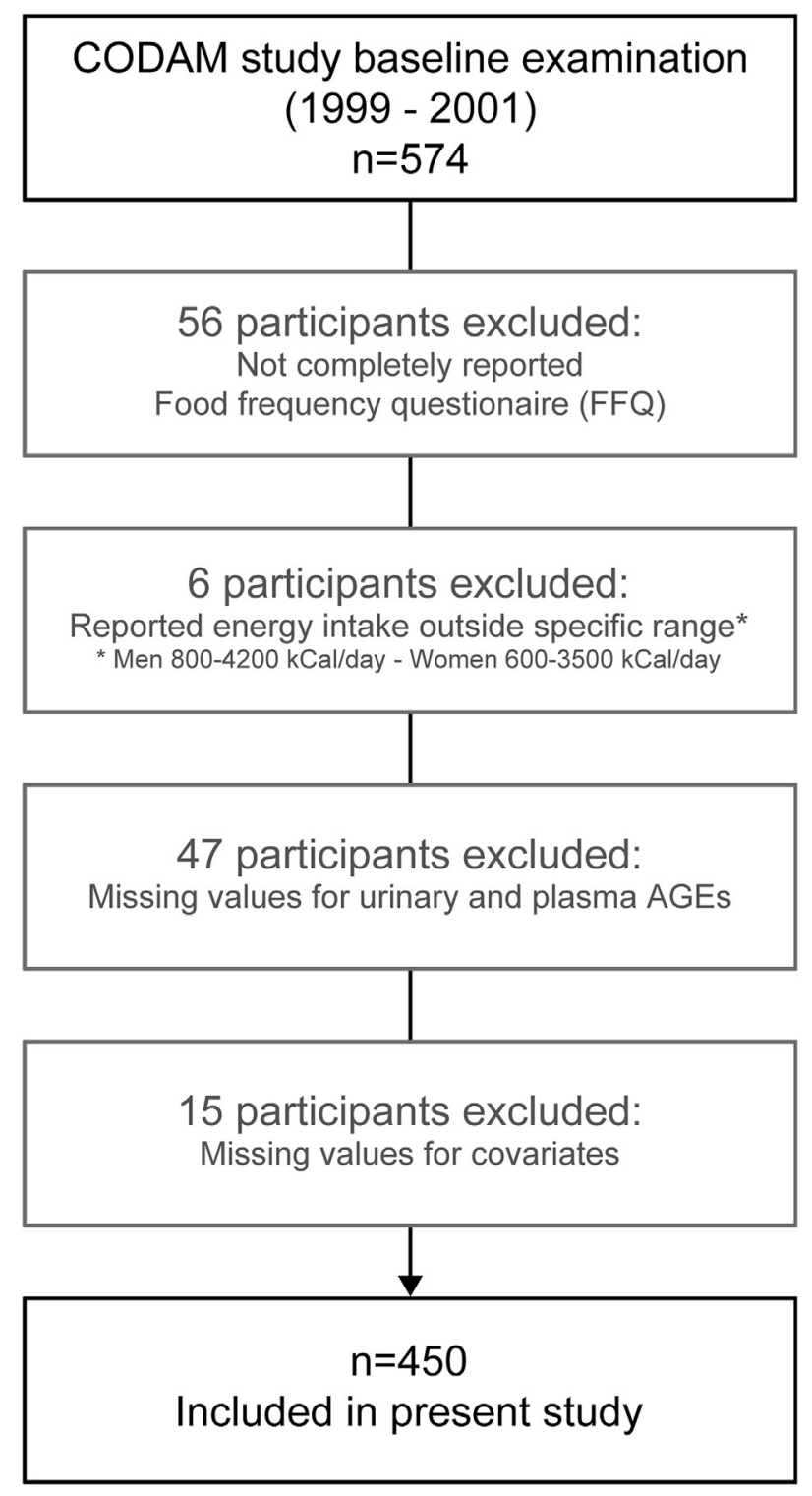

Fig. 1. Flowchart for the exclusion of participants in the current CODAM study.

medication). Plasma creatinine levels were measured with the Jaffe diagnostic test (Roche Diagnostics, Mannheim, Germany), and the estimated glomerular filtration rate (eGFR) was calculated using the Chronic Kidney Disease Epidemiology Collaboration (CKD-EPI) equation [27]. Plasma malondialdehyde (MDA) levels were measured with a reagent kit for high-performance liquid chromatography analyses (Chromsystems Instruments and Chemicals, Munich, Germany), and total antioxidative status (TAS) was measured in serum with an enzymatic kit (Randox Diagnostics, County Antrim, U.K.). LDL cholesterol was calculated with the Friedewald formula [28], after measurement of fasting total cholesterol, HDL-cholesterol and triglyceride levels.

All subjects gave written informed consent. The study was approved by the local Medical Ethical Committee of the University of Maastricht and University Hospital Maastricht.

\subsection{Food, plasma and urinary AGE quantification}

Protein-bound AGEs in individual food items and in plasma, and free AGEs in plasma and in urine were analyzed as described in 
detail elsewhere $[23,29]$. In short, foods were obtained from local supermarkets or restaurants and prepared according to the instructions on the label. For UPLC-MS/MS analysis a representative sample of each food item, equivalent to $5 \mathrm{mg}$ of protein, was used. For protein-bound and free plasma AGEs, $25 \mu \mathrm{L}$ and $50 \mu \mathrm{L}$ plasma was used, respectively. Forty microliters were used for free urinary AGE analysis. All samples were derivatized with butanolic hydrochloric acid and subsequently detected in ESI positive multiple reaction monitoring (MRM) mode using a Xevo TQ MS (Waters, Milford, USA). Quantification of CML, CEL and MG-H1 was performed by calculating the peak area ratio of each unlabeled peak area to the corresponding internal standard peak area. In plasma, the intra- and inter-assay variation of protein-bound CML and CEL were between 4.8 and $9.7 \%$ and for free CML, CEL and MG-H1 between 2.8 and $7.1 \%$. In urine, the intra- and inter-assay variation of free CML, CEL and MG-H1 were between 3.7 and 6.6\%. In food matrix, the intra- and inter-assay variation of protein-bound CML, CEL and MG-H1 were between 1.7 and $29.1 \%$.

\subsection{Assessment of AGE intake}

For UPLC-MS/MS protein-bound AGE analysis, food items were selected based on the items included in the FFQ of CODAM, which queried 194 foods commonly consumed in the Netherlands. Each food item in the FFQ was quantified as grams of food per day and analyzed for AGE content. The AGE intake was estimated for each participant by multiplying the food intake in g/day with the concentration of AGEs in $\mathrm{mg} / \mathrm{g}$ in each representative individual food item. To calculate the total AGE intake per participant, the estimated AGE levels of the various food items were added together. Some of the food items had unspecific descriptions in the FFQ (e.g. "sweet spreads"). These items were further defined as an average of this food group (e.g. for "sweet spreads" the average AGE content of apple syrup, chocolate spread, chocolate sprinkles, fruit sprinkles and jam was used). Moreover, some of the food items in the FFQ were not analyzed for AGEs. These food items were matched with food items based on ingredient profile. To this end, estimation was made for the AGE content of these missing food items.

\subsection{Statistical analyses}

All statistical analyses were carried out using the IBM SPSS Statistics Software, version 23.0 (IBM Corporation, Armonk, NY, USA). General characteristics of the CODAM population were compared across tertiles of the dietary AGE score with the use of ANOVA or $\chi^{2}$-tests, for continuous or categorical data, respectively. We $\log _{\mathrm{e}}$-normalized all plasma and urinary AGEs to reduce the potential influence of outliers and to obtain a normal distribution, needed for calculation of Z-scores. An AGE score was calculated that represents an individual's overall intake of AGEs via their habitual diet. For this, first the Z-scores were calculated for each dietary AGE (CML, CEL and MG-H1) as follows: for each individual dietary AGE, a Z-score was calculated according to the formula: [(individual dietary AGE - population mean dietary AGE)/population standard deviation dietary AGE]. The resulting Z-scores, of each dietary AGE (CML, CEL and MG-H1), were then averaged into an overall dietary AGE Z-score and this overall dietary AGE Z-score was subsequently standardized.

We used linear regression analyses to investigate the association between dietary and plasma or urinary AGE levels, after adjustments for participant characteristics (age, sex, glucose metabolism status and waist circumference: model 1) and additionally for kidney function (estimated glomerular filtration rate (eGFR): model 2 ), and further for potential dietary and lifestyle confounding factors (energy intake and protein-, saturated fat-, carbohydrate- and fiber-intake, all macronutrients expressed as energy percentage and smoking, physical activity and alcohol intake: model 3), and for potential confounding by lipid metabolism and oxidative stress (LDL-cholesterol, malondialdehyde (MDA) and total antioxidant status (TAS): model 4). Participants with missing values $(n=14)$ on co-variates were excluded listwise. We also tested whether associations differed for sex (sex $\times$ dietary AGE), eGFR $(e G F R \times$ dietary AGE) and the presence of impaired glucose metabolism or diabetes (presence of impaired glucose metabolism or diabetes $\times$ dietary AGE), by adding interaction terms to our models ( $p$-values for interaction were $<0.1$ ). Overall, we found no consistent interactions (data not shown).

\section{Results}

Table 1 shows the general characteristics of the total population of the CODAM study as stratified according to tertiles of dietary AGEs. Although we observed important quantitative differences in dietary AGE levels, with MG-H1 being most abundant, we observed strong correlations between the AGE intake (CML vs CEL $r_{\text {pearson: }}$ : 0.811, CML vs MG-H1 $\mathrm{r}_{\text {pearson }}$ : 0.795 and CEL vs MG-H1 $\mathrm{r}_{\text {pearson: }}$ : 0.880 ; for all $\mathrm{p}<0.001$ ). Plasma free-, plasma protein-bound- and urinary AGEs did not differ between the tertiles of dietary AGEs (Table 1). Male participants had higher intake of dietary AGEs $(\mathrm{p}<0.001$, Table 1$)$. In addition, HDL cholesterol, protein intake and fiber intake were lower in the individuals with higher intake of dietary AGEs ( $p<0.05$, Table 1$)$ and saturated fat-, energy- and alcohol intake were higher in the individuals with higher intake of dietary AGEs ( $\mathrm{p}<0.05$, Table 1$)$.

\subsection{Associations between dietary AGE intake and protein-bound plasma AGEs}

After adjustment for age, sex, glucose metabolism status and waist circumference, we found no significant association between dietary CML and protein-bound plasma CML levels (Table 2, model 1). Further adjustment for eGFR did not change these results (Table 2, model 2). In the fully adjusted model we observed a weak positive association of dietary CML and protein-bound plasma CML, but this was not significant (Table 2, model 4). We observed similar findings for dietary CEL and protein-bound CEL (Table 2).

\subsection{Associations between dietary AGE intake and free plasma AGEs}

After adjustment for age, sex, glucose metabolism status and waist circumference we observed positive associations between dietary intake of CML, CEL and MG-H1 and their free levels in plasma (Table 3, model 1). Further adjustment for eGFR (Table 3, model 2), energy- and macro-nutrient intake, lifestyle factors, lipid metabolism and markers of oxidative stress (Table 3, model 3 and 4) did not change the results overall. In the fully adjusted model, these associations were approximately twice as strong for CML, CEL and MG-H1 (Table 3, model 4 vs model 1).

\subsection{Associations between dietary AGE intake and free urinary AGEs}

In line with the findings for free plasma AGEs, higher dietary intake of CML, CEL and MG-H1 were associated with higher urinary CML, CEL and MG-H1 levels (Table 4, model 1-4). Adjustment for eGFR did not change the results (Table 4, model 2).

\section{Discussion}

This study is, to our knowledge, the first to demonstrate that higher dietary intake of CML, CEL and MG-H1, as estimated with a 
Table 1

Clinical characteristics of total study population.

\begin{tabular}{|c|c|c|c|c|c|}
\hline & \multirow{2}{*}{$\begin{array}{l}\text { Total population } \\
(\mathrm{n}=450)\end{array}$} & \multicolumn{4}{|l|}{ Dietary AGE tertiles } \\
\hline & & Lowest $(\mathrm{n}=151)$ & Middle $(\mathrm{n}=151)$ & Highest $(\mathrm{n}=148)$ & $P_{\text {trend }}$ \\
\hline Age (years) & $59.4 \pm 7.0$ & $60.1 \pm 6.9$ & $59.0 \pm 6.7$ & $58.9 \pm 7.4$ & 0.140 \\
\hline $\operatorname{Sex}(\mathrm{m} / \mathrm{f} ; \%)$ & $60.0 / 40.0$ & $45.7 / 54.3$ & $59.6 / 40.4$ & $75.0 / 25.0$ & $<0.001$ \\
\hline NGM/IGM/T2DM (\%) & $53.6 / 22.7 / 23.8$ & $50.3 / 23.2 / 26.5$ & $56.3 / 18.5 / 25.2$ & $54.1 / 26.4 / 19.6$ & 0.376 \\
\hline Body mass index $\left(\mathrm{kg} / \mathrm{m}^{2}\right)$ & $28.3 \pm 4.2$ & $28.5 \pm 4.5$ & $28.2 \pm 4.1$ & $28.3 \pm 3.9$ & 0.690 \\
\hline Waist circumference $(\mathrm{cm})$ & $98.6 \pm 11.6$ & $97.8 \pm 12.1$ & $98.4 \pm 11.7$ & $99.6 \pm 11.0$ & 0.162 \\
\hline Fasting glucose $(\mathrm{mmol} / \mathrm{L})$ & $6.0 \pm 1.4$ & $6.0 \pm 1.3$ & $6.0 \pm 1.5$ & $6.0 \pm 1.4$ & 0.823 \\
\hline HbA1c $(\%)$ & $5.9 \pm 0.8$ & $5.9 \pm 0.6$ & $6.0 \pm 0.9$ & $6.0 \pm 0.8$ & 0.671 \\
\hline Total cholesterol (mmol/L) & $5.2 \pm 0.9$ & $5.3 \pm 0.9$ & $5.1 \pm 1.0$ & $5.2 \pm 0.8$ & 0.553 \\
\hline HDL cholesterol $(\mathrm{mmol} / \mathrm{L})$ & $1.20 \pm 0.35$ & $1.25 \pm 0.36$ & $1.22 \pm 0.35$ & $1.15 \pm 0.33$ & 0.010 \\
\hline LDL cholesterol (mmol/L) & $3.29 \pm 0.86$ & $3.32 \pm 0.90$ & $3.21 \pm 0.89$ & $3.35 \pm 0.79$ & 0.757 \\
\hline Triglycerides $(\mathrm{mmol} / \mathrm{L})$ & $1.4(1.0-1.9)$ & $1.4(1.0-1.9)$ & $1.4(1.0-2.0)$ & $1.4(1.0-1.9)$ & 0.969 \\
\hline Current smoking (\%) & 20.2 & 21.1 & 22.3 & 18.5 & 0.756 \\
\hline Malondialdehyde $(\mu \mathrm{mol} / \mathrm{L})$ & $0.18 \pm 0.05$ & $0.18 \pm 0.06$ & $0.17 \pm 0.05$ & $0.18 \pm 0.05$ & 0.887 \\
\hline Total antioxidant status (mmol/L) & $1.08 \pm 0.10$ & $1.08 \pm 0.10$ & $1.07 \pm 0.10$ & $1.10 \pm 0.10$ & 0.090 \\
\hline SBP (mmHg) & $139.3 \pm 18.7$ & $141.4 \pm 17.9$ & $138.4 \pm 19.9$ & $138.2 \pm 18.0$ & 0.144 \\
\hline $\mathrm{DBP}(\mathrm{mmHg})$ & $81.3 \pm 9.0$ & $81.6 \pm 8.2$ & $80.4 \pm 9.5$ & $82.0 \pm 9.3$ & 0.697 \\
\hline eGFR $\left(\mathrm{mL} / \mathrm{min} / 1.73 \mathrm{~m}^{2}\right)$ & $91.8 \pm 17.3$ & $93.1 \pm 23.9$ & $90.8 \pm 12.6$ & $91.4 \pm 12.7$ & 0.379 \\
\hline Glucose-lowering treatment (\%) & 13.3 & 13.2 & 14.6 & 12.2 & 0.828 \\
\hline Lipid-lowering treatment (\%) & 19.1 & 19.9 & 21.2 & 16.2 & 0.527 \\
\hline Blood pressure-lowering treatment (\%) & 38.0 & 41.7 & 39.1 & 33.1 & 0.292 \\
\hline Energy intake (kcal/day) & $2191.9 \pm 601.0$ & $1677.9 \pm 382.0$ & $2148.2 \pm 351.6$ & $2750.8 \pm 478.5$ & $<0.001$ \\
\hline Protein intake (\% energy) & $15.5 \pm 2.2$ & $15.9 \pm 2.5$ & $15.6 \pm 2.1$ & $15.1 \pm 1.9$ & 0.002 \\
\hline Carbohydrate intake (\% energy) & $44.0 \pm 6.2$ & $43.8 \pm 6.9$ & $44.4 \pm 5.4$ & $43.9 \pm 6.2$ & 0.943 \\
\hline Saturated fat intake (\% energy) & $14.6 \pm 2.5$ & $14.2 \pm 2.6$ & $14.6 \pm 2.5$ & $15.0 \pm 2.5$ & 0.006 \\
\hline Fibre intake (\% energy) & $2.36 \pm 0.49$ & $2.47 \pm 0.51$ & $2.34 \pm 0.49$ & $2.25 \pm 0.45$ & $<0.001$ \\
\hline Alcoholic drinks (g/day) & $107(11-280)$ & $71(6-225)$ & $100(12-284)$ & $135(29-304)$ & 0.032 \\
\hline Physical activity ( $\mathrm{min} \times$ intensity/week) & $1800(1058-2835)$ & $1703(1043-2655)$ & $1890(1140-2865)$ & $1837(956-2966)$ & 0.404 \\
\hline Plasma free CML (nmol/L) & $78(60-99)$ & $77(57-101)$ & $77(63-99)$ & $80(60-97)$ & 0.626 \\
\hline Plasma free CEL (nmol/L) & $45(37-58)$ & $45(35-59)$ & $44(38-55)$ & $47(38-60)$ & 0.496 \\
\hline Plasma free MG-H1 (nmol/L) & $121(86-173)$ & $113(82-167)$ & $120(91-166)$ & $126(88-191)$ & 0.117 \\
\hline Plasma protein-bound CML ( $\mathrm{nmol} / \mathrm{mmol}$ lys) & $35(30-41)$ & $35(29-41)$ & $34(31-41)$ & $35(29-42)$ & 0.861 \\
\hline Plasma protein-bound CEL (nmol/mmol lys) & $24(19-29)$ & $22(18-27)$ & $24(19-29)$ & $24(20-30)$ & 0.056 \\
\hline Urinary free CML (nmol/mmol creatinine) & $954(749-1220)$ & $944(735-1257)$ & $941(739-1244)$ & $966(756-1175)$ & 0.980 \\
\hline Urinary free CEL (nmol/mmol creatinine) & $519(409-645)$ & $519(428-635)$ & $510(384-631)$ & $540(405-675)$ & 0.296 \\
\hline Urinary free MG-H1 (nmol/mmol creatinine) & $2284(1593-3270)$ & $2251(1587-3286)$ & $2274(1535-3190)$ & $2421(1664-3397)$ & 0.627 \\
\hline Dietary CML (mg/day) & $3.10 \pm 1.03$ & $2.08 \pm 0.47$ & $3.07 \pm 0.44$ & $4.17 \pm 0.77$ & $<0.001$ \\
\hline Dietary CEL (mg/day) & $2.32 \pm 0.77$ & $1.58 \pm 0.31$ & $2.24 \pm 0.28$ & $3.15 \pm 0.60$ & $<0.001$ \\
\hline Dietary MG-H1 (mg/day) & $21.7 \pm 6.69$ & $15.2 \pm 2.85$ & $20.9 \pm 2.42$ & $28.9 \pm 5.09$ & $<0.001$ \\
\hline
\end{tabular}

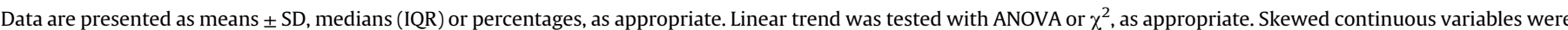
analyzed with Kruskal Wallis (triglycerides, and the AGEs) were $\log _{\mathrm{e}}$-transformed prior to analyses.

Table 2

Associations between dietary AGEs and protein-bound plasma AGEs.

\begin{tabular}{|c|c|c|c|c|}
\hline & \multirow[t]{2}{*}{ Model } & \multicolumn{3}{|c|}{ Protein-bound plasma CML } \\
\hline & & $\beta$ & $95 \% \mathrm{CI}$ & $p$ \\
\hline \multirow{7}{*}{ Dietary CML } & Crude & 0.039 & $-0.054 ; 0.128$ & 0.42 \\
\hline & 1 & 0.048 & $-0.041 ; 0.133$ & 0.30 \\
\hline & 2 & 0.046 & $-0.042 ; 0.131$ & 0.32 \\
\hline & 3 & 0.122 & $-0.042 ; 0.277$ & 0.15 \\
\hline & 4 & 0.130 & $-0.032 ; 0.283$ & 0.12 \\
\hline & Model & \multicolumn{3}{|c|}{ Protein-bound plasma CEL } \\
\hline & & $\beta$ & $95 \% \mathrm{CI}$ & $p$ \\
\hline \multirow[t]{5}{*}{ Dietary CEL } & Crude & 0.112 & $0.017 ; 0.199$ & 0.02 \\
\hline & 1 & 0.105 & $0.005 ; 0.197$ & 0.04 \\
\hline & 2 & 0.101 & $0.002 ; 0.194$ & 0.05 \\
\hline & 3 & 0.136 & $-0.030 ; 0.293$ & 0.11 \\
\hline & 4 & 0.112 & $-0.050 ; 0.268$ & 0.18 \\
\hline
\end{tabular}

Data were analyzed using linear regression analyses. $\beta$ s are expressed as 1 SD increase of plasma AGE per 1 SD increase of dietary AGE. All plasma AGEs were Lnnormalized in all analyses.

Model 1: adjusted for age, sex, glucose metabolism status, waist circumference. Model 2: model $1+$ eGFR.

Model 3: model 2 + total energy-, protein-, saturated fat-, carbohydrate- and fiberintake, smoking, physical activity, alcohol intake.

Model 4: model 3 + LDL cholesterol, malondialdehyde, total antioxidant status.
FFQ is associated significantly with higher free plasma and urinary levels of AGEs, as measured with UPLC-MS/MS. We found a weak non-significant association of dietary AGEs with their corresponding protein bound plasma AGEs. In the current study we estimated dietary CML, CEL and MG-H1. Since these compounds were highly correlated, despite quantitative differences, we assume that these three AGEs were well-representative for dietary AGE contents.

Studies so far have suggested that dietary AGEs are associated with circulating AGEs [13,15-18,30]. Our current study expands on these findings in several important ways. First, we have used a state-of-the-art UPLC-MS/MS technique to analyze three different dietary AGEs and circulating AGEs. Moreover, we performed UPLCMS/MS plasma and urinary analyses in a large and well-defined cohort study to investigate the associations between three different dietary AGEs and plasma and urinary AGEs. Another major strength of our study is that we were able to use a database of AGEs, as measured with UPLC-MS/MS [23], in 190 food items to calculate the habitual intake of dietary AGEs based on a FFQ. However, one important limitation of our study was that our FFQ did not include detailed information about food preparation techniques on all food items. We and others have shown that differences in these cooking techniques and duration of heating are fundamental in the formation of AGEs in food $[5,23,31]$. However, approximately $90 \%$ of the 
Table 3

Associations between dietary AGEs and free plasma AGEs.

\begin{tabular}{|c|c|c|c|c|}
\hline & \multirow[t]{2}{*}{ Model } & \multicolumn{3}{|c|}{ Free plasma CML } \\
\hline & & $\beta$ & $95 \% \mathrm{CI}$ & $p$ \\
\hline \multirow[t]{7}{*}{ Dietary CML } & Crude & 0.055 & $-0.039 ; 0.147$ & 0.26 \\
\hline & 1 & 0.099 & $0.006 ; 0.190$ & 0.04 \\
\hline & 2 & 0.094 & $0.004 ; 0.183$ & 0.04 \\
\hline & 3 & 0.224 & $0.057 ; 0.386$ & 0.01 \\
\hline & 4 & 0.253 & $0.086 ; 0.415$ & $<0.01$ \\
\hline & Model & \multicolumn{3}{|c|}{ Free plasma CEL } \\
\hline & & $\beta$ & $95 \% \mathrm{CI}$ & $p$ \\
\hline \multirow[t]{7}{*}{ Dietary CEL } & Crude & 0.086 & $-0.008 ; 0.176$ & 0.07 \\
\hline & 1 & 0.098 & $0.003 ; 0.188$ & 0.04 \\
\hline & 2 & 0.086 & $-0.007 ; 0.174$ & 0.07 \\
\hline & 3 & 0.208 & $0.053 ; 0.353$ & 0.01 \\
\hline & 4 & 0.194 & $0.040 ; 0.339$ & 0.01 \\
\hline & Model & \multicolumn{3}{|c|}{ Free plasma MG-H1 } \\
\hline & & $\beta$ & $95 \% \mathrm{CI}$ & $p$ \\
\hline \multirow[t]{5}{*}{$\overline{\text { Dietary MG-H1 }}$} & $\overline{\text { Crude }}$ & 0.127 & $0.033 ; 0.219$ & 0.01 \\
\hline & 1 & 0.150 & $0.056 ; 0.241$ & $<0.01$ \\
\hline & 2 & 0.135 & $0.043 ; 0.224$ & $<0.01$ \\
\hline & 3 & 0.239 & $0.085 ; 0.390$ & $<0.01$ \\
\hline & 4 & 0.223 & $0.069 ; 0.373$ & $<0.01$ \\
\hline
\end{tabular}

Data were analyzed using linear regression analyses. $\beta$ s are expressed as 1 SD increase of plasma AGE per 1 SD increase of dietary AGE. All plasma AGEs were Lnnormalized in all analyses.

Model 1: adjusted for age, sex, glucose metabolism status, waist circumference. Model 2: model $1+$ eGFR.

Model 3: model 2 + total energy-, protein-, saturated fat-, carbohydrate- and fiberintake, smoking, physical activity, alcohol intake.

Model 4: model 3 + LDL cholesterol, malondialdehyde, total antioxidant status.

Table 4

Associations between dietary AGEs and urinary free AGEs.

\begin{tabular}{|c|c|c|c|c|}
\hline & \multirow[t]{2}{*}{ Model } & \multicolumn{3}{|c|}{ Urinary free CML } \\
\hline & & $\beta$ & $95 \% \mathrm{CI}$ & $p$ \\
\hline \multirow{7}{*}{ Dietary CML } & Crude & 0.045 & $-0.049 ; 0.138$ & 0.35 \\
\hline & 1 & 0.127 & $0.033 ; 0.218$ & 0.01 \\
\hline & 2 & 0.127 & $0.033 ; 0.218$ & 0.01 \\
\hline & 3 & 0.211 & $0.038 ; 0.380$ & 0.02 \\
\hline & 4 & 0.223 & $0.049 ; 0.393$ & 0.01 \\
\hline & Model & \multicolumn{3}{|c|}{ Urinary free CEL } \\
\hline & & $\beta$ & $95 \% \mathrm{CI}$ & $p$ \\
\hline \multirow[t]{7}{*}{ Dietary CEL } & Crude & 0.056 & $-0.037 ; 0.146$ & 0.25 \\
\hline & 1 & 0.121 & $0.024 ; 0.211$ & 0.01 \\
\hline & 2 & 0.124 & $0.027 ; 0.214$ & 0.01 \\
\hline & 3 & 0.189 & $0.027 ; 0.340$ & 0.02 \\
\hline & 4 & 0.180 & $0.019 ; 0.332$ & 0.03 \\
\hline & Model & \multicolumn{3}{|c|}{ Urinary free MG-H1 } \\
\hline & & $\beta$ & $95 \% \mathrm{CI}$ & $p$ \\
\hline \multirow[t]{5}{*}{$\overline{\text { Dietary MG-H1 }}$} & $\overline{\text { Crude }}$ & 0.066 & $-0.028 ; 0.157$ & 0.17 \\
\hline & 1 & 0.134 & $0.039 ; 0.224$ & $<0.01$ \\
\hline & 2 & 0.134 & $0.043 ; 0.228$ & $<0.01$ \\
\hline & 3 & 0.205 & $0.045 ; 0.357$ & 0.01 \\
\hline & 4 & 0.196 & $0.037 ; 0.349$ & 0.02 \\
\hline
\end{tabular}

Data were analyzed using linear regression analyses. $\beta$ s are expressed as $1 \mathrm{SD}$ increase of urinary AGE per 1 SD increase of dietary AGE. All urinary AGEs were Lnnormalized in all analyses.

Model 1: adjusted for age, sex, glucose metabolism status, waist circumference. Model 2: model $1+$ eGFR.

Model 3: model 2 + total energy-, protein-, saturated fat-, carbohydrate- and fiberintake, smoking, physical activity, alcohol intake.

Model 4: model 3 + LDL cholesterol, malondialdehyde, total antioxidant status.
FFQ food items were either uncooked, such as fruit, raw vegetables and drinks or were pre-processed foods which were produced by different manufacturers, such as cookies, bread or peanut butter. Our FFQ consisted of only $10 \%$ of food items which have to be prepared by the participant itself, such as meat, fish, potatoes or pasta. We have included detailed information on the preparation of potatoes in the FFQ, such as boiling, frying or baking. Unfortunately, no detailed information of the preparation, in particular duration of heating, of meat or fish was available. However, our dAGE database [23], which was used to estimate AGE-intake as calculated with FFQ data, consisted of meat- and fish products which were prepared according to the instructions of the manufacturer's label or using the most common preparation technique. Perhaps this will have led to a source of variance in estimating the dietary AGE content, but this was only true for a minority of the food items. Nonetheless, we still found clear and consistent associations between estimated dietary AGE intake and plasma AGE levels.

Our crude analysis only revealed an association between higher dietary AGEs and higher plasma and urinary AGE levels. Particularly after adjustment for sex, age, glucose metabolism and waist (model 1 ), and further adjustment for the major macronutrients and lifestyle factors (model 3) even stronger associations were found between dietary AGEs and free plasma and urinary AGEs. The strong effect of confounding factors on the reported associations may at least partly explain conflicting findings between previous studies which have not taken into account these confounding factors $[19,20]$.

Dietary AGE-modified proteins are mainly digested into free glycated and non-glycated amino acids and small peptides [32] and thus protein-bound dietary AGEs are expected to enter the circulation predominately in the free form. Subsequently, these AGEs are excreted in the urine [16]. We found no association of dietary AGEs with protein-bound AGEs in plasma, suggesting that the vast majority of the protein-bound AGEs in the human body are formed by the non-enzymatic reaction of glucose, $\alpha$-oxoaldehydes and other saccharide derivatives with proteins, nucleotides and lipids. On the contrary, we found an association of dietary AGEs with free AGEs in plasma. This is in accordance with a recent study which has showed that free plasma AGEs were mainly released from the protein-bound dietary AGEs and hereby enter the circulation predominantly [32]. In line, we found that associations between dietary AGEs and free plasma AGEs are stronger than with protein-bound plasma AGEs. Two intervention studies were in line with these results $[13,16]$. Birlouez-Aragon et al., reported a significant increase of $7 \%$ protein-bound plasma CML after administering a high AGE diet versus a significant increase of $40 \%$ free urinary CML [16]. Furthermore, the associations between the estimated dietary AGE intake with free plasma AGEs is in line with animal intervention studies [33,34]. In these studies, lowand high-AGE diets were tested in animals and significantly increased levels of free plasma CML, but not protein-bound plasma CML, were found $[33,34]$. In the same study, increased plasma levels of sRAGE and a pro-inflammatory response was reported after administering a high-AGE diet [33] which implicates important biological consequences.

In humans, the beneficial effects of a low AGE-diet have been described $[8,13,35]$. If a high-AGE diet in humans, and contemporaneously increased levels of free plasma AGEs, can lead to an increased risk for development of chronic diseases is still under investigation. In our observational study we investigated the association of a habitual diet with similar results.

In summary, we have shown that higher levels of dietary AGEs were significantly associated with higher levels of free plasma 
and urinary AGEs. These findings are an important step in understanding the metabolic transit of these dietary AGEs. Several studies indicate that dietary AGEs are associated with poor health [8-10,16,20]. Future prospective studies should address whether dietary AGEs are associated with adverse outcomes such as accelerated development of cardiovascular disease, diabetes and other age-related diseases. This line of investigation may eventually lead to new dietary recommendations for both the general public and perhaps specific patients groups in particular.

\section{Statement of authorship}

\section{Scheijen: wrote paper.}

Hanssen: contributed to discussion and reviewed and edited the manuscript.

Greevenbroek: reviewed and edited the manuscript.

Van der Kallen: reviewed and edited the manuscript.

Feskens: reviewed and edited the manuscript.

Stehouwer: reviewed and edited the manuscript.

Schalkwijk: designed the study, reviewed and edited the manuscript and had primary responsibility for final content.

\section{Funding sources}

None.

\section{Conflict of interest statement}

Authors have no potential conflicts of interest.

\section{Acknowledgements}

None.

\section{References}

[1] van Eupen MG, Schram MT, Colhoun HM, Scheijen JL, Stehouwer CD, Schalkwijk CG. Plasma levels of advanced glycation endproducts are associated with type 1 diabetes and coronary artery calcification. Cardiovasc Diabetol 2013:12:149.

[2] Hanssen NM, Wouters K, Huijberts MS, Gijbels MJ, Sluimer JC, Scheijen JL, et al. Higher levels of advanced glycation endproducts in human carotid atherosclerotic plaques are associated with a rupture-prone phenotype. Eur Heart J 2014;35:1137-46.

[3] Gopal P, Reynaert NL, Scheijen JL, Engelen L, Schalkwijk CG, Franssen FM, et al. Plasma advanced glycation end-products and skin autofluorescence are increased in COPD. Eur Respir J 2014;43:430-8.

[4] Maillard LC. Action des acides aminés sur les sucres: formation des mélanoidines paar voie méthodique. CR Acad Sci 1912;154:66-8.

[5] Poulsen MW, Hedegaard RV, Andersen JM, de Courten B, Bugel S, Nielsen J et al. Advanced glycation endproducts in food and their effects on health. Food Chem Toxicol 2013;60:10-37.

[6] Cordain L, Eaton SB, Sebastian A, Mann N, Lindeberg S, Watkins BA, et al. Origins and evolution of the Western diet: health implications for the 21st century. Am J Clin Nutr 2005;81:341-54.

[7] Clarke RE, Dordevic AL, Tan SM, Ryan L, Coughlan MT. Dietary advanced glycation end products and risk factors for chronic disease: a systematic review of randomised controlled trials. Nutrients 2016;8.

[8] de Courten B, de Courten MP, Soldatos G, Dougherty SL, Straznicky N, Schlaich M, et al. Diet low in advanced glycation end products increases insulin sensitivity in healthy overweight individuals: a double-blind, randomized, crossover trial. Am J Clin Nutr 2016;103:1426-33.

[9] Angoorani P, Ejtahed HS, Mirmiran P, Mirzaei S, Azizi F. Dietary consumption of advanced glycation end products and risk of metabolic syndrome. Int J Food Sci Nutr 2016;67:170-6.

[10] Lubitz I, Ricny J, Atrakchi-Baranes D, Shemesh C, Kravitz E, Liraz-Zaltsman S, et al. High dietary advanced glycation end products are associated with poorer spatial learning and accelerated Abeta deposition in an Alzheimer mouse model. Aging Cell 2016;15:309-16.

[11] Gaens KH, Stehouwer CD, Schalkwijk CG. Advanced glycation endproducts and its receptor for advanced glycation endproducts in obesity. Curr Opin Lipidol 2013;24:4-11.

[12] Verzijl N, DeGroot J, Ben ZC, Brau-Benjamin O, Maroudas A, Bank RA, et al. Crosslinking by advanced glycation end products increases the stiffness of the collagen network in human articular cartilage: a possible mechanism through which age is a risk factor for osteoarthritis. Arthritis Rheum 2002;46:114-23.

[13] Mark AB, Poulsen MW, Andersen S, Andersen JM, Bak MJ, Ritz C, et al. Consumption of a diet low in advanced glycation endproducts for 4 weeks improves insulin sensitivity in overweight women. Diabetes Care 2014;37: $88-95$.

[14] Poulsen MW, Bak MJ, Andersen JM, Monosik R, Giraudi-Futin AC, Holst JJ, et al. Effect of dietary advanced glycation end products on postprandial appetite, inflammation, and endothelial activation in healthy overweight individuals. Eur J Nutr 2014;53:661-72.

[15] Klenovics KS, Boor P, Somoza V, Celec P, Fogliano V, Sebekova K. Advanced glycation end products in infant formulas do not contribute to insulin resistance associated with their consumption. PLoS One 2013;8:e53056.

[16] Birlouez-Aragon I, Saavedra G, Tessier FJ, Galinier A, Ait-Ameur L, Lacoste F, et al. A diet based on high-heat-treated foods promotes risk factors for diabetes mellitus and cardiovascular diseases. Am J Clin Nutr 2010;91: 1220-6.

[17] Uribarri J, Stirban A, Sander D, Cai W, Negrean M, Buenting CE, et al. Single oral challenge by advanced glycation end products acutely impairs endothelial function in diabetic and nondiabetic subjects. Diabetes Care 2007;30: 2579-82.

[18] Macias-Cervantes MH, Rodriguez-Soto JM, Uribarri J, Diaz-Cisneros FJ, Cai W, Garay-Sevilla ME. Effect of an advanced glycation end product-restricted diet and exercise on metabolic parameters in adult overweight men. Nutrition 2015;31:446-51.

[19] Chao PC, Huang CN, Hsu CC, Yin MC, Guo YR. Association of dietary AGEs with circulating AGEs, glycated LDL, IL-1alpha and MCP-1 levels in type 2 diabetic patients. Eur J Nutr 2010;49:429-34.

[20] Negrean M, Stirban A, Stratmann B, Gawlowski T, Horstmann T, Gotting C et al. Effects of low- and high-advanced glycation endproduct meals on macro- and microvascular endothelial function and oxidative stress in patients with type 2 diabetes mellitus. Am J Clin Nutr 2007;85:1236-43.

[21] Charissou A, Ait-Ameur L, Birlouez-Aragon I. Evaluation of a gas chromatography/mass spectrometry method for the quantification of carboxymethyllysine in food samples. J Chromatogr A 2007;1140:189-94.

[22] Tareke E, Forslund A, Lindh $\mathrm{CH}$, Fahlgren C, Ostman E. Isotope dilution ESI-LC MS/MS for quantification of free and total nepsilon-(1-carboxymethyl)-Llysine and free nepsilon-(1-carboxyethyl)-L-lysine: comparison of total nepsilon-(1-carboxymethyl)-L-lysine levels measured with new method to ELISA assay in gruel samples. Food Chem 2013;141:4253-9.

[23] Scheijen JL, Clevers E, Engelen L, Dagnelie PC, Brouns F, Stehouwer CD, et al. Analysis of advanced glycation endproducts in selected food items by ultraperformance liquid chromatography tandem mass spectrometry: Presentation of a dietary AGE database. Food Chem 2016;190:1145-50.

[24] Jacobs M, van Greevenbroek MM, van der Kallen CJ, Ferreira I, Feskens EJ, Jansen EH, et al. The association between the metabolic syndrome and alanine amino transferase is mediated by insulin resistance via related metabolic intermediates (the Cohort on Diabetes and Atherosclerosis Maastricht [CODAM] study). Metabolism 2011;60:969-75.

[25] Ocke MC, Bueno-de-Mesquita HB, Pols MA, Smit HA, van Staveren WA Kromhout D. The Dutch EPIC food frequency questionnaire. II. Relative validity and reproducibility for nutrients. Int J Epidemiol 1997;26(Suppl. 1): S49-58.

[26] Maessen DE, Hanssen NM, Scheijen JL, van der Kallen CJ, van Greevenbroek MM, Stehouwer CD, et al. Post-glucose load plasma alphadicarbonyl concentrations are increased in individuals with impaired glucose metabolism and type 2 diabetes: the CODAM study. Diabetes Care 2015;38: 913-20.

[27] Levey AS, Bosch JP, Lewis JB, Greene T, Rogers N, Roth D. A more accurate method to estimate glomerular filtration rate from serum creatinine: a new prediction equation. Modification of Diet in Renal Disease Study Group. Ann Intern Med 1999;130:461-70.

[28] Friedewald WT, Levy RI, Fredrickson DS. Estimation of the concentration of low-density lipoprotein cholesterol in plasma, without use of the preparative ultracentrifuge. Clin Chem 1972;18:499-502.

[29] Hanssen NM, Engelen L, Ferreira I, Scheijen JL, Huijberts MS, van Greevenbroek MM, et al. Plasma levels of advanced glycation endproducts nepsilon-(carboxymethyl)lysine, nepsilon-(carboxyethyl)lysine, and pentosidine are not independently associated with cardiovascular disease in individuals with or without type 2 diabetes: the Hoorn and CODAM studies. J Clin Endocrinol Metab 2013;98:E1369-73.

[30] Sebekova K, Saavedra G, Zumpe C, Somoza V, Klenovicsova K, BirlouezAragon I. Plasma concentration and urinary excretion of $N$ epsilon-(carboxymethyl)lysine in breast milk- and formula-fed infants. Ann N Y Acad Sci 2008; 1126:177-80.

[31] Uribarri J, Woodruff S, Goodman S, Cai W, Chen X, Pyzik R, et al. Advanced glycation end products in foods and a practical guide to their reduction in the diet. J Am Diet Assoc 2010;110:911-6. e12.

[32] Hellwig M, Matthes R, Peto A, Lobner J, Henle T. N-epsilon-fructosyllysine and $\mathrm{N}$-epsilon-carboxymethyllysine, but not lysinoalanine, are available for absorption after simulated gastrointestinal digestion. Amino Acids 2014;46: 289-99.

[33] Elmhiri G, Mahmood DF, Niquet-Leridon C, Jacolot P, Firmin S, Guigand L, et al. Formula-derived advanced glycation end products are involved in the 
development of long-term inflammation and oxidative stress in kidney of IUGR piglets. Mol Nutr food Res 2015;59:939-47.

[34] Roncero-Ramos I, Delgado-Andrade C, Tessier FJ, Niquet-Leridon C, Strauch C Monnier VM, et al. Metabolic transit of N(epsilon)-carboxymethyl-lysine after consumption of AGEs from bread crust. Food \& Funct 2013;4:1032-9.
[35] Vlassara H, Cai W, Tripp E, Pyzik R, Yee K, Goldberg L, et al. Oral AGE restriction ameliorates insulin resistance in obese individuals with the metabolic syndrome: a randomised controlled trial. Diabetologia 2016;59: 2181-92. 